\title{
BMJ Open Association between systemic sclerosis and peripheral arterial disease: a nationwide observation retrospective claim records cohort study in Taiwan
}

\author{
Ming-Chia Hsieh, ${ }^{1}$ Hsin-Hung Chen, ${ }^{2,3}$ Tzu-Yi Chou, ${ }^{4}$ Ta-Wei Su, ${ }^{5}$ Cheng-Li Lin, ${ }^{6}$ \\ Chia-Hung Kao (1) ${ }^{7}$
}

To cite: Hsieh M-C, Chen $\mathrm{H}-\mathrm{H}$, Chou T-Y, et al. Association between systemic sclerosis and peripheral arterial disease: a nationwide observation retrospective claim records cohort study in Taiwan. BMJ Open 2021;11:e048149. doi:10.1136/ bmjopen-2020-048149

- Prepublication history and additional supplemental material for this paper are available online. To view these files, please visit the journal online (http://dx.doi.org/10.1136/ bmjopen-2020-048149)

$\mathrm{M}-\mathrm{CH}$ and $\mathrm{H}-\mathrm{HC}$ contributed equally.

Received 21 December 2020 Accepted 13 September 2021

Check for updates

(C) Author(s) (or their employer(s)) 2021. Re-use permitted under CC BY-NC. No commercial re-use. See rights and permissions. Published by BMJ.

For numbered affiliations see end of article.

Correspondence to

Dr Chia-Hung Kao;

d10040@mail.cmuh.org.tw

\section{ABSTRACT}

Objectives Recent studies have proposed associations between systemic sclerosis (SSc) and atherosclerosis and between SSc and cardiovascular disease. However, in Asia, no large-scale studies have focused on the association between peripheral arterial disease (PAD) and SSc.

Setting A nationwide observation retrospective cohort study.

Participants The National Health Insurance Research Database was used for selecting patients diagnosed with SSc from 2000 to 2011. Patients diagnosed with PAD before the index date were excluded.

Primary and secondary outcome measures The SSc cohort comprised 1106 patients with SSc, and the nonSSc cohort comprised 4424 matched controls. The Cox proportional hazards regression model was used for analysing the adjusted risk of PAD between the case and control patients.

Results The SSc cohort exhibited a significantly higher risk ( $\mathrm{HR}=2.15,95 \% \mathrm{Cl}=1.47$ to 3.14 ) of PAD than did the non-SSc cohort. Patients with heart failure exhibited the highest risk of $\mathrm{PAD}$ (adjusted $\mathrm{HR}=2.10,95 \% \mathrm{Cl}=1.20$ to 3.70). Moreover, even without any comorbidities, the SSc cohort exhibited a significantly higher risk (adjusted $\mathrm{HR}=4.17$ fold, $95 \% \mathrm{Cl}=1.98$ to 8.77 ) of PAD than did the non-SSc cohort.

Conclusion SSc is associated with a significantly high risk of PAD. Further studies are required to reduce the PAD risk among patients with SSc.

\section{INTRODUCTION}

Systemic sclerosis (SSc) is a chronic multiorgan autoimmune disease of elusive pathogenesis. SSc can be of diffuse or limited form according to the extent of skin fibrosis. One of the severe manifestations of SSc is vasculopathy, and the onset of vasculopathy in SSc precedes other manifestations, including fibrosis. Furthermore, the manifestations of vasculopathy can be recognised from appearances: digital ulcers, malformed capillaries and Raynaud phenomenon at the early stage, which then progress to significant internal organ involvement, including pulmonary
Strengths and limitations of this study

- Our study was the first nationwide, populationbased cohort study to focus on peripheral arterial disease (PAD) and systemic sclerosis (SSc).

- Our study showed significantly different risks of incident PAD in the SSc in Taiwan compared with Eastern country.

- Some limitations were the diagnoses only documented by International Classification of Diseases, Ninth Revision, Clinical Modification with risk factors interfered by statistical analyses instead of smoking habits and the ankle-brachial index investigation.

arterial hypertension (PAH) and renal crisis. It results in serious malfunctions and, ultimately, the failure of almost all organs. ${ }^{1} \mathrm{SSc}$ separates patients into two main groups such as diffuse cutaneous SSc and limited cutaneous SSc. Mortality is higher in patients with diffuse type than limited type. PAH is a severe complication of SSc, and the leading cause of mortality. The rate of mortality is nearly $15 \%$ among patients with $\mathrm{SSc}$ with $\mathrm{PAH}^{2}{ }^{3}$ The epidemiological characteristics of SSc significantly vary according to regions and races. For instance, the prevalence of SSc in adults has been estimated to be 7-489 per million, and the annual incidence rate has been estimated to be $0.6-242$ per million. ${ }^{45}$ Peripheral arterial disease $(\mathrm{PAD})$, a manifestation of atherosclerosis, is one of the most life-threatening but underdiagnosed disorders. ${ }^{6}{ }^{7}$ Intermittent claudication and calf discomfort are the classic PAD symptoms; however, asymptomatic PAD may be present in up to $50 \%$ of patients with PAD. ${ }^{89}$ Moreover, patients with symptomatic and asymptomatic PAD exhibit an increased risk of cardiovascular and all-cause mortality. ${ }^{9}$ A large-scale systematic review and meta-analysis emphasised that PAD is a global problem, affecting at least 202 
million persons. ${ }^{10}$ Irrespective of any preceding ischaemic event in the brain or heart, PAD has been considered a risk factor for cardiovascular disease that is equivalent to coronary artery disease (CAD).$^{11-13}$ The established risk factors for PAD include older age, cigarette smoking, hypertension (HTN), diabetes mellitus (DM) and dyslipidaemia. ${ }^{914}$

Several studies, including a systematic review, ${ }^{15}$ have revealed that patients with SSc have an increased risk of atherosclerosis by microvascular injury and diffuse fibrosis of the skin and internal organs ${ }^{16}$ and the associated possible pathogenic mechanisms underlying the atherosclerotic process in SSc have been proposed and discussed. ${ }^{1718}$ Current study showed that $76 \%$ of patients with SSc had haemodynamic arterial lower limb abnormalities related to macrovascular and/or microvascular impairment and that $28 \%$ had vascular stiffness by measuring ankle-brachial index, toe pressure and toebrachial index. ${ }^{19}$ A study examined the death certificates of all French patients with SSc to determine causes of death between 2000 and 2011. The result of the research identified 2719 French certificates of deaths related to SSc, mainly from cardiac (31\%) and respiratory (18\%) causes, and an increase in SSc-specific mortality over time. ${ }^{20}$ However, no large-scale study has focused on the precise association between SSc and PAD. Therefore, we elucidated the association between SSc and the risk of PAD in this nationwide retrospective cohort study.

\section{MATERIALS AND METHODS}

\section{Patient and public involvement}

The Taiwan government established the National Health Insurance (NHI) programme in 1995, covering over 99\% of the Taiwanese population..$^{21}$ The NHI Research Database (NHIRD) was derived from the NHI programme managed by the Bureau of National Health Insurance and maintained by the National Health Research Institutes. The NHIRD has high accuracy and validity and therefore has also been previously used. ${ }^{22} 23$ Diseases are defined in the NHIRD according to the International Classification of Diseases, Ninth Revision, Clinical Modification (ICD-9-CM).

\section{Patients}

We enrolled patients who were newly diagnosed with SSc (ICD-9-CM 710.1) from 2000 to 2011 according to the American College of Rheumatology (ACR) diagnostic criteria. The Registry for Catastrophic Illness Patient Database (RCIPD), an NHIRD subset, authenticated the SSc diagnosis, and the patients were identified from the RCIPD. In Taiwan, patients who fit the ACR diagnostic criteria for SSc can obtain a catastrophic illness card through their rheumatologists after undergoing peerreviewed examination. Patients who have this card are exempted from some of their SSc-related medical costs. The index date was set as the date of SSc diagnosis. Moreover, patients aged $<20$ years, diagnosed with PAD
(ICD-9-CM 440.2, 440.3, 440.8, 440.9, 443, 444.22, 444.8, 447.8 and 447.9; excluding 443.0) before the index date, or with missing information on sex or age were excluded. Each patient with SSc was frequency matched with four non-SSc controls with regard to age (in 5-year intervals), sex and the year of SSc diagnosis. The index date for nonSSc subjects was randomly appointed a month and day with the same index year of the matched SSc cases. The same exclusion criteria were applied for establishing the non-SSc cohort.

\section{Outcome and comorbidities}

The primary outcome was newly diagnosed PAD obtained from claims records. All patients were observed from the index date to the date of the primary outcome; loss to follow-up; death; withdrawal from the NHI programme; or 31 December 2011. The pre-existing comorbidities included DM (ICD-9-CM 250), HTN (ICD-9-CM 401-405), hyperlipidaemia (ICD-9-CM 272), chronic obstructive pulmonary disease (COPD; ICD-9-CM 491, 492 and 496), heart failure (ICD-9-CM 428), CAD (ICD-9-CM 410-414), stroke (ICD-9-CM 430-438) and asthma (ICD-9-CM 493).

\section{Statistical analysis}

All statistical analyses were performed using SAS software, V.9.4. A two-tailed $p$ value of $<0.05$ was considered significant. We used the $\chi^{2}$ test to determine the differences in categorical demographic variables and comorbidities between the SSc and non-SSc cohorts. The Student's t-test was used to examine the mean ages and follow-up period between both cohorts. The cumulative incidence survival functions for PAD development in the SSc and non-SSc cohorts were assessed using Kaplan-Meier analysis, and the difference between the two cohorts was compared using the log-rank test. The incidence densities of PAD (per 1000 person-years) were estimated for both cohorts. Moreover, univariable and multivariable Cox proportional hazards regression analysis was used to estimate the HRs and 95\% CIs of PAD development for the SSc cohorts compared with the non-SSc cohorts. The multivariable models were simultaneously adjusted for age, sex, DM, HTN, hyperlipidaemia, COPD, heart failure, $\mathrm{CAD}$, and asthma.

\section{RESULTS}

We enrolled 1106 and 4424 patients in the SSc and nonSSc cohorts, respectively, with similar sex and age distributions (table 1). SSc was more prevalent in women (72.3\%), and $44.9 \%$ of the patients were aged $\leq 49$ years. The mean ages of the SSc and non-SSc cohorts were $52.2 \pm 14.5$ and $51.7 \pm 14.8$ years, respectively. Compared with the non-SSc cohort, the SSc cohort exhibited a significantly higher prevalence of COPD, heart failure, CAD, and asthma (all $\mathrm{p}<0.001)$.

The mean follow-up periods were $4.83(\mathrm{SD}=3.58)$ and $5.60(\mathrm{SD}=3.54)$ years for the SSc and non-SSc cohorts, respectively (data not shown). Figure 1 presents the 
Table 1 Comparison of demographics and comorbidity between patients and controls with systemic sclerosis

\begin{tabular}{|c|c|c|c|}
\hline & $\begin{array}{l}\text { Control } \\
\text { subjects } \\
(n=4424)\end{array}$ & $\begin{array}{l}\text { Systemic } \\
\text { sclerosis } \\
(n=1106)\end{array}$ & \multirow[b]{2}{*}{$P$ value } \\
\hline & n (\%) & n (\%) & \\
\hline Gender & & & 0.99 \\
\hline Female & 3200 (72.3) & 800 (72.3) & \\
\hline Male & $1244(27.7)$ & 306 (27.7) & \\
\hline Age, year & & & 0.99 \\
\hline$\leq 49$ & 1984 (44.9) & 496 (44.9) & \\
\hline $50-64$ & 1488 (33.6) & 372 (33.6) & \\
\hline$>65$ & 952 (21.5) & 238 (21.5) & \\
\hline Mean (SD) & 51.7 (14.8) & $52.2(14.5)$ & $0.30^{*}$ \\
\hline $\begin{array}{l}\text { Follow-up time } \\
\text { (SD) }\end{array}$ & $5.60(3.54)$ & $3.86(3.42)$ & $<0.001^{*}$ \\
\hline
\end{tabular}

Comorbidity

\begin{tabular}{lrrc} 
Diabetes & $398(9.00)$ & $92(8.32)$ & 0.48 \\
Hypertension & $1363(30.8)$ & $334(30.2)$ & 0.69 \\
Hyperlipidaemia & $856(19.4)$ & $220(19.9)$ & 0.68 \\
COPD & $356(8.05)$ & $182(16.5)$ & $<0.001$ \\
Heart failure & $104(2.35)$ & $83(7.50)$ & $<0.001$ \\
CAD & $620(14.0)$ & $202(18.3)$ & $<0.001$ \\
Stroke & $153(3.46)$ & $28(2.53)$ & 0.12 \\
Asthma & $257(5.81)$ & $102(9.22)$ & $<0.001$ \\
\hline
\end{tabular}

$\chi^{2}$ test was used for the analysis.

*T-test.

CAD, coronary artery disease; COPD, chronic obstructive pulmonary disease.

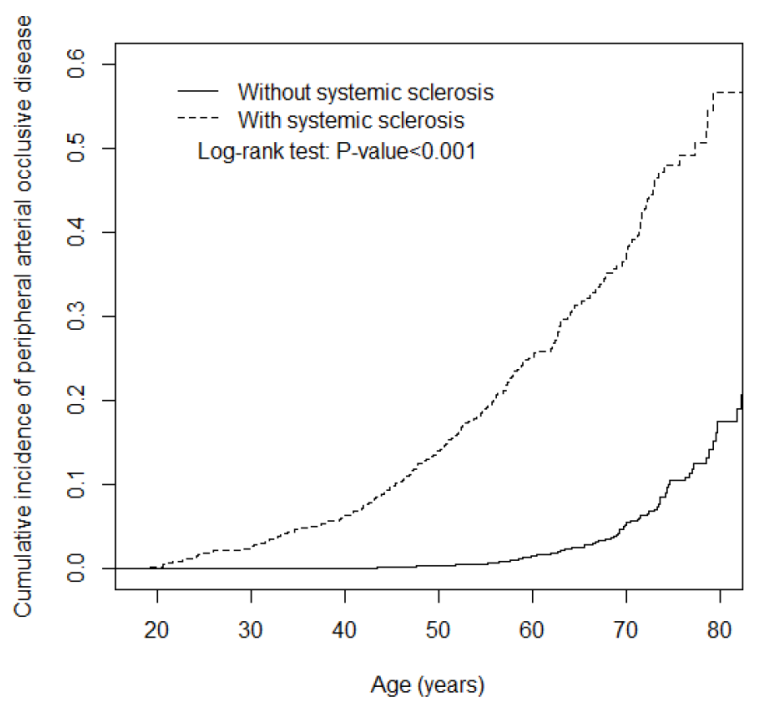

Figure 2 Cumulative incidence of peripheral arterial disease for patients with (dashed line) or without (solid line) systemic sclerosis versus index age.

cumulative PAD incidence curve for the two cohorts and indicates that the incidence curve of $\mathrm{PAD}$ was significantly higher for the SSc cohort than for the non-SSc cohort (log-rank test, $\mathrm{p}<0.001)$ from the beginning to the end of the follow-up period. Even the risk for PAD between SSc and non-SSc groups was significantly higher through the ascending of $\mathrm{PAD}$ index age in figure 2 (log-rank test, $\mathrm{p}<0.001)$.

Moreover, the cumulative PAD incidence for the SSc and non-SSc cohorts was $7 \%$ and $3 \%$, respectively, at the end of the follow-up period.

Table 2 lists the PAD incidence densities of both cohorts: the SSc-to-non-SSc HRs of PAD by sex, age and comorbidities. The overall incidence density rate of PAD in the SSc cohort was 7.68 per 1000 person-years, which was higher than that in the non-SSc cohort (3.55 per 1000 personyears), with an adjusted HR (aHR) of 2.15 (95\% CI=1.47 to 3.14). Furthermore, the highest variable-specific PAD incidence rate in the SSc cohort was observed in men (14.0 per 1000 person-years). The sex-specific risk of PAD in the SSc cohort relative to that in the non-SSc cohort was significant for both women $(\mathrm{aHR}=1.74,95 \% \mathrm{CI}=1.08$ to 2.80) and men (aHR=3.28, 95\% CI=1.73 to 6.23). Moreover, the age-specific risk of PAD in the SSc cohort relative to that in the non-SSc cohort was significant for aged 50-64 groups and aged $>65$ groups ( $\leq 49$ years, $\mathrm{aHR}=4.71,95 \% \mathrm{CI}=2.02$ to $11.0 ; 50-64$ years, $\mathrm{aHR}=2.91$, $95 \% \mathrm{CI}=1.59$ to 5.33 ). In patients without comorbidities, the risk of PAD was 4.17 -fold higher in the SSc cohort than in the non-SSc cohort (95\% CI=1.98 to 8.77) (online supplemental table).

Table 3 illustrates the crude HRs and aHRs of PAD associated with SSc. The aHRs were calculated after adjusting for sex, age and baseline comorbidities. The crude HRs and aHRs of PAD associated with DM, HTN, hyperlipidaemia, COPD, heart failure, CAD, stroke and asthma are also listed. The aHRs were calculated after

Figure 1 Cumulative incidence of peripheral arterial disease for patients with (dashed line) or without (solid line) systemic sclerosis versus follow-up years. 
Table 2 Incidence and adjusted HR of peripheral arterial disease stratified by sex and age compared between systemic sclerosis cohort and non-systemic sclerosis cohort

\begin{tabular}{|c|c|c|c|c|c|c|c|c|}
\hline \multirow[b]{2}{*}{ Variables } & \multicolumn{3}{|c|}{ Control subjects } & \multicolumn{3}{|c|}{ Systemic sclerosis } & \multicolumn{2}{|c|}{ Compared with control subjects } \\
\hline & $\begin{array}{l}\text { No of } \\
\text { events }\end{array}$ & PY & Rate $^{\dagger}(95 \% \mathrm{Cl})$ & $\begin{array}{l}\text { No of } \\
\text { events }\end{array}$ & PY & Rate $^{\dagger}(95 \% \mathrm{Cl})$ & $\begin{array}{l}\text { Crude HR } \\
(95 \% \mathrm{Cl})\end{array}$ & $\begin{array}{l}\text { Adjusted } \mathrm{HR}^{\ddagger} \\
(95 \% \mathrm{Cl})\end{array}$ \\
\hline \multicolumn{9}{|l|}{ Gender } \\
\hline Female & 64 & 18501 & 3.46 (3.11 to 3.85$)$ & 24 & 4130 & 5.81 (4.68 to 7.22$)$ & $1.67(1.04 \text { to } 2.66)^{*}$ & $1.74(1.08 \text { to } 2.80)^{*}$ \\
\hline Male & 24 & 6283 & 3.82 (3.20 to 4.56$)$ & 17 & 1211 & 14.0 (10.0 to 19.6$)$ & $3.49(1.87 \text { to } 6.50)^{\star \star \star}$ & $3.28(1.73 \text { to } 6.23)^{\star \star \star ~}$ \\
\hline$\leq 49$ & 10 & 12033 & $0.83(0.71$ to 0.97$)$ & 13 & 2833 & 4.59 (3.45 to 6.10$)$ & $5.47(2.40 \text { to } 12.5)^{\star \star \star}$ & $4.71(2.02 \text { to } 11.0)^{\star \star \star}$ \\
\hline $50-64$ & 29 & 7864 & 3.69 (3.15 to 4.32$)$ & 19 & 1664 & $11.4(8.45$ to 15.4$)$ & $3.04(1.70 \text { to } 5.42)^{\star \star *}$ & $2.91(1.59 \text { to } 5.33)^{\star \star \star}$ \\
\hline$>65$ & 49 & 4888 & $10.0(8.39$ to 12.0$)$ & 9 & 843 & 10.7 (7.22 to 15.8$)$ & 1.01 (0.50 to 2.06$)$ & 0.89 (0.43 to 1.83$)$ \\
\hline \multicolumn{9}{|c|}{ Comorbidity ${ }^{\S}$} \\
\hline
\end{tabular}

${ }^{*} \mathrm{p}<0.05,{ }^{* *} \mathrm{p}<0.01,{ }^{* * *} \mathrm{p}<0.001$.

†Incidence rate, per 1000 person-years.

$\ddagger$ Adjusted HR : multivariable analysis including age, gender and comorbidities of diabetes, hypertension, hyperlipidaemia, COPD, heart failure, CAD, stroke and asthma.

§Comorbidity: patients with any one of the comorbidities diabetes, hypertension, hyperlipidaemia, COPD, heart failure, CAD, stroke and asthma were classified as the comorbidity group.

CAD, coronary artery disease; COPD, chronic obstructive pulmonary disease; PY, person-years.

adjusting for sex, age, SSc and other baseline comorbidities. The crude HR of PAD increased by 1.06 -fold (95\% $\mathrm{CI}=1.04$ to 1.07 ) with age (in 1-year intervals). Moreover, among the crude HRs, all comorbidities, were associated with a higher risk of PAD. However, after adjustment for sex, age, SSc and other baseline comorbidities, only hyperlipidaemia and heart failure were associated with a higher risk of PAD. A stratified analysis of the follow-up period revealed that the risk of PAD in the SSc cohort compared with that in the non-SSc cohort peaked during the first follow-up year $(\mathrm{aHR}=3.23,95 \%$ $\mathrm{CI}=1.60$ to 6.51 ; table 4 ). The risk of PAD existed even

Table 3 Cox model with hazard ratios and 95\% Cls of peripheral arterial disease associated with systemic sclerosis and covariates

\begin{tabular}{|c|c|c|c|c|}
\hline \multirow[b]{2}{*}{ Variable } & \multicolumn{2}{|c|}{ Crude } & \multicolumn{2}{|c|}{ Adjusted $^{\dagger}$} \\
\hline & HR & $(95 \% \mathrm{Cl})$ & HR & $(95 \% \mathrm{Cl})$ \\
\hline Systemic sclerosis & 2.12 & $(1.47 \text { to } 3.08)^{\star \star \star}$ & 2.14 & $(1.47 \text { to } 3.13)^{\star \star \star}$ \\
\hline Sex (women vs men) & 1.39 & (0.96 to 2.01$)$ & & \\
\hline Age, years & 1.06 & $(1.04 \text { to } 1.07)^{\star \star \star}$ & 1.05 & $(1.03 \text { to } 1.06)^{\star \star *}$ \\
\hline \multicolumn{5}{|c|}{ Baseline comorbidities (yes vs no) } \\
\hline Diabetes & 3.11 & $(2.02 \text { to } 4.79)^{\star \star \star}$ & 1.46 & (0.92 to 2.33$)$ \\
\hline Hypertension & 3.28 & $(2.31 \text { to } 4.64)^{\star \star \star}$ & 1.16 & (0.75 to 1.80$)$ \\
\hline Hyperlipidaemia & 3.27 & $(2.31 \text { to } 4.64)^{\star \star \star}$ & 1.71 & $(1.15 \text { to } 2.53)^{\star \star}$ \\
\hline COPD & 1.72 & $(1.05 \text { to } 2.84)^{\star}$ & 0.69 & (0.41 to 1.18$)$ \\
\hline Heart failure & 6.14 & $(3.68 \text { to } 10.2)^{\star \star \star}$ & 2.10 & $(1.20 \text { to } 3.70)^{\star \star}$ \\
\hline CAD & 3.74 & $(2.62 \text { to } 5.35)^{\star \star \star}$ & 1.47 & (0.96 to 2.25$)$ \\
\hline Stroke & 2.23 & $(1.04 \text { to } 4.77)^{\star}$ & 0.89 & (0.41 to 1.94$)$ \\
\hline Asthma & 2.17 & $(1.27 \text { to } 3.72)^{\star \star}$ & 1.15 & (0.65 to 2.05$)$ \\
\hline
\end{tabular}

Crude HR refers to relative $\mathrm{HR}$.

${ }^{*} \mathrm{p}<0.05,{ }^{* *} \mathrm{p}<0.01,{ }^{* * *} \mathrm{p}<0.001$.

†Adjusted HR : multivariable analysis including age, and comorbidities of diabetes, hypertension, hyperlipidaemia, COPD, heart failure, CAD, stroke and asthma.

CAD, coronary artery disease; COPD, chronic obstructive pulmonary disease. 
Table 4 Trends of peripheral arterial disease by stratified follow-up years

\begin{tabular}{|c|c|c|c|c|c|c|c|c|}
\hline $\begin{array}{l}\text { Follow } \\
\text { time, } \\
\text { years }\end{array}$ & \multicolumn{3}{|c|}{ Control subjects } & \multicolumn{3}{|c|}{ Systemic sclerosis } & \multicolumn{2}{|c|}{ Compared with control subjects } \\
\hline$\leq 1$ & 18 & 4137 & 4.35 & 15 & 985 & 15.2 & $3.48(1.75 \text { to } 6.90)^{\star * *}$ & $3.23(1.60 \text { to } 6.51)^{\star \star *}$ \\
\hline $1-3$ & 27 & 6954 & 3.88 & 11 & 1559 & 7.05 & $1.82(0.90$ to 3.67$)$ & 1.78 (0.88 to 3.62$)$ \\
\hline $4-5$ & 22 & 5493 & 4.01 & 6 & 1151 & 5.21 & $1.30(0.53$ to 3.20$)$ & $1.50(0.60$ to 3.77$)$ \\
\hline$>5$ & 21 & 8201 & 2.56 & 9 & 1644 & 5.47 & 2.13 (0.98 to 4.65$)$ & $2.36(1.06 \text { to } 5.29)^{*}$ \\
\hline
\end{tabular}

${ }^{*} \mathrm{p}<0.05,{ }^{* *} \mathrm{p}<0.01,{ }^{* * *} \mathrm{p}<0.001$.

†Rate refers to incidence rate per 1000 person-years.

$\neq$ Crude HR refers to relative HR.

$\S$ Adjusted HR: multivariable analysis including age, and comorbidities of diabetes, hypertension, hyperlipidaemia, COPD, heart failure, CAD and asthma.

CAD, coronary artery disease; COPD, chronic obstructive pulmonary disease.

beyond 5 years of follow-up $(\mathrm{aHR}=2.36,95 \% \mathrm{CI}=1.06$ to 5.29).

\section{DISCUSSION}

Taiwan has a high prevalence of PAD. ${ }^{24-26}$ This study was the first in Asia to investigate the association between SSc and the risk of PAD according to a longitudinal, population-based, nationwide cohort. The epidemiological characteristics of SSc significantly vary with the geographical location. Previous studies have reported that the SSc prevalence in Taiwan was approximately 38 per million persons, which was higher than that reported in a systematic literature review conducted in Japan ( 7 cases per million persons) but lower than that reported in Italy (489 cases per million persons). ${ }^{47}$ During the 12-year follow-up, the cumulative incidence of PAD consistently increased and exhibited a higher trend in the SSc cohort than in the non-SSc cohort (figure 1). Moreover, the risk of incident PAD in the SSc cohort increased by approximately 11-fold compared with that in the non-SSc cohort at the end of the follow-up period; this observation is in accordance with that of a previous study. ${ }^{28}$ Man et $a t^{28}$ reported that the risks of incident PAD in patients with SSc increased by approximately fourfold compared with those in patients without SSc. However, the risks of incident PAD in the SSc and non-SSc cohorts is significantly different in Taiwan.

In our study, COPD, heart failure, CAD, stroke and asthma were significantly more prevalent in the SSc group than in the non-SSc group. After adjustment for sex, age and comorbidities, the SSc group exhibited a 2.15-fold higher risk of PAD than did the non-SSc group. Furthermore, the number of patients with PAD in our study might have been underestimated because PAD is typically underdiagnosed. ${ }^{6}$ Hence, the actual effect of SSc on PAD might be more serious than that reported here. Our finding that patients with SSc may be more predisposed to $\mathrm{PAD}$ is consistent with the findings of previous studies conducted in Europe, the USA and Asia. ${ }^{29-31}$ Moreover, our finding is in accordance with that of the study by Zeng et al, which demonstrated that SSc is an independent risk factor for PAD. Nordin et $a l^{30}$ examined 111 patients with SSc in Stockholm County and indicated that patients with SSc, particularly those with anticentromere antibodies, exhibited an increased risk of PAD. However, they did not compare the cumulative incidence of PAD in these patients with that in patients without SSc.

Several factors may increase the risk of PAD in patients with SSc. First, the SSc cohort exhibited a significantly higher incidence of comorbidities than did the non-SSc cohort (table 1). Moreover, COPD, heart failure, CAD and stroke were associated with an increased risk of $\mathrm{PAD}^{1132-37}$; thus, patients with these comorbidities might have an increased risk of PAD compared with patients without these comorbidities. A study with the online databases such as MEDLINE and EMBASE until December 2018 showed the comorbidities including atherosclerosis and $\mathrm{CAD}$, dyslipidaemia, infections, cancer, psychological burden and osteoporosis in SSc. ${ }^{38}$

Second, several studies have proposed potential reasons for endothelial dysfunction, atherosclerosis and vasculopathy in patients with SSc, including downregulated endothelial nitric oxide synthase and increased endothelial microparticle-associated diminished nitric oxide synthesis $^{39}{ }^{40}$ elevated oxidised low-density lipoprotein and endothelin ${ }^{41}$ and increased inflammatory mediators, including tumour necrosis factor-alpha and interleukin-6. ${ }^{42}$ Additionally, Boin et al proposed that the antibody anti- $\beta 2$-glycoprotein $\mathrm{I}$ is associated with PAD in patients with SSc. ${ }^{43}$ The aforementioned changes that are caused by SSc potentially explain the stronger association between SSc and subsequent PAD compared with patients without SSc. Skin ulcers are frequent in SSc due to vasculopathy and Raynaud's phenomenon which means a involvement of microcirculation. Patients with SSc have higher PAD risk. The cornerstone of SSc vascular derangement may be related with large vessels involvement and vice versa. All of these possible mechanisms above could explain the results of our study which showed that in patients without comorbidities, the risk of 
PAD was 4.17 -fold higher in the SSc cohort than in the non-SSc cohort (95\% CI=1.98 to 8.77).

After adjustment for sex, age, SSc and other baseline comorbidities, only heart failure and hyperlipidaemia were associated with a higher risk of PAD in our study. Previous studies indicated that heart involvement such as primary myocardial involvement is very common in SSc. Repeated local ischaemic injury causing subsequent irreversible myocardial fibrosis is the main heart failure for patients with SSc. Cardiac involvement is recognised as a poor prognostic factor and the leading causes of mortality in patients with $\mathrm{SSc}^{44}$ Cardiac involvement is a frequent visceral complication of SSc. Myocardial fibrosis which can progress leading to arrhythmia, heart dysfunction to heart failure is the pathophysiologic hallmark and the poor prognostic factor. ${ }^{45}$ In other way, chronic inflammation might result in premature atherosclerosis. Other manifestations including arrhythmia and heart failure might have a silent progress in patients with SSc. ${ }^{46}$ Another basic study also mentioned the relationship between asymmetric dimethylarginine (ADMA) and inflammatory syndrome. ADMA is an endogenous nitric oxide synthase inhibitor contributing or causing the endothelial dysfunction. ${ }^{47}$ One study mentioned the heart failure and PAD. The reduction in the pulsatile flow and continuous flow-induced endothelial dysfunction in patients with heart failure could induce the PAD. ${ }^{48}$ Again, hyperlipidaemia is the established factors for $\mathrm{PAD}^{9} 14$ and our study confirmed the same result in patients with SSc. Another claim records from Danish also showed the cardiovascular manifestations of SSc such as PAD or myocardial infarction. ${ }^{49}$ Although smoking could not be analysed in our study due to data limitation, it remained the risk factor for PAD and Raynaud's phenomenon. Smoking caused the atherosclerosis through the mechanisms with oxidative stress and inflammation resulting in the morphological and functional dysfunction of the vascular endothelium. ${ }^{50}$

One strength of this study is that this is the first nationwide, population-based cohort study to focus on PAD in patients with SSc in Asia, with systematic data collection and a sufficient sample size to facilitate an effective investigation. The second strength of this study is that the risks of incident PAD in the SSc and non-SSc cohorts are significantly different in Taiwan compared with those in the other Asian countries. ${ }^{28}$ This indicates that physicians should be aware of the higher risk of PAD in patients with SSc. This study has some limitations. First, the diagnoses recorded in the NHIRD were documented using ICD-9-CM only, and information on risk factors that may have interfered with analyses, such as smoking habits, family history and the ankle-brachial index, could not be investigated. Due to the data restriction and limitation, our study could not collect the smoking habit for the analysis of smoking, SSc and PAD, but we used COPD and asthma to represent smoking-related diseases and to reduce the confounding bias. Second, we attempted to adjust and control for all interfering factors; however, the confounding effects of the aforementioned comorbidities of PAD were probably not completely controlled.

In summary, patients with SSc have an independently higher risk of PAD. In our study, early-onset SSc or patients in middle age (40-50 years) would be necessary to follow-up via monthly or quarterly compressed health surveillance within 1 year for PAD screen.

\section{Author affiliations}

${ }^{1} \mathrm{U}$ Come Joint Clinic, Taichung, Taiwan

${ }^{2}$ Department of Internal Medicine, Asia University Hospital, Taichung, Taiwan ${ }^{3}$ School of Medicine, Chung Shan Medical University;Chung Sheng clinic, Nantou, Taiwan; Department of Law, Providence University, Taichung, Taiwan

${ }^{4}$ Department of Physical Medicine and Rehabilitation, China Medical University Hospital, Taichung, Taiwan

${ }^{5}$ Department of Surgery, Chang Gung University, Taoyuan, Taiwan

${ }^{6}$ Management Office for Health Data, China Medical University Hospital, Taichung, Taiwan

${ }^{7}$ Graduate Institute of Biomedical Sciences, College of Medicine, China Medical University;Department of Nuclear Medicine and PET Center, China Medical University Hospital;Department of Bioinformatics and Medical Engineering, Asia University;Center of Augmented Intelligence in Healthcare, China Medical University Hospital, Taichung, Taiwan

Contributors M-CH, H-HC, T-YC, T-WS and C-HK were involved in study conception and design. Administrative support was given by $\mathrm{M}-\mathrm{CH}, \mathrm{H}-\mathrm{HC}, \mathrm{T}-\mathrm{YC}$, T-WS and C$\mathrm{HK}$. Collection and data assembly along with data analysis and interpretation were done by C-LL and C-HK. M-CH, H-HC, T-YC, T-WS, C-LL and C-HK were involved in manuscript writing. Final approval of the manuscript was given by all the authors.

Funding This study is supported in part by Taiwan Ministry of Health and Welfare Clinical Trial Center (MOHW109-TDU-B-212-1 14 004), China Medical University Hospital (CMU107-ASIA-19, DMR-109-231, DMR-110-089); MOST Clinical Trial Consortium for Stroke (MOST 108-2321-B-039-003), Tseng-Lien Lin Foundation, Taichung, Taiwan. The funders had no role in the study design, data collection and analysis, the decision to publish or preparation of the manuscript. No additional external funding was received for this study.

Competing interests None declared.

Patient consent for publication Not applicable.

Ethics approval This retrospective cohort study complied with the guidelines of the Declaration of Helsinki and was approved by the Research Ethics Committee of China Medical University (CMUH104-REC2-115-CR4).

Provenance and peer review Not commissioned; externally peer reviewed.

Data availability statement Data may be obtained from a third party and are not publicly available. The dataset used in this study is held by the Taiwan Ministry of Health and Welfare (MOHW). The Ministry of Health and Welfare must approve our application to access this data. Any researcher interested in accessing this dataset can submit an application form to the Ministry of Health and Welfare requesting access. Please contact the staff of MOHW (Email: stcarolwu@mohw.gov.tw) for further assistance. Taiwan Ministry of Health and Welfare Address: No.488, Sec. 6 , Zhongxiao E. Rd., Nangang Dist., Taipei City 115, Taiwan (ROC). Phone: +886-28590-6848. All relevant data are within the paper.

Supplemental material This content has been supplied by the author(s). It has not been vetted by BMJ Publishing Group Limited (BMJ) and may not have been peer-reviewed. Any opinions or recommendations discussed are solely those of the author(s) and are not endorsed by BMJ. BMJ disclaims all liability and responsibility arising from any reliance placed on the content. Where the content includes any translated material, BMJ does not warrant the accuracy and reliability of the translations (including but not limited to local regulations, clinical guidelines, terminology, drug names and drug dosages), and is not responsible for any error and/or omissions arising from translation and adaptation or otherwise.

Open access This is an open access article distributed in accordance with the Creative Commons Attribution Non Commercial (CC BY-NC 4.0) license, which permits others to distribute, remix, adapt, build upon this work non-commercially, and license their derivative works on different terms, provided the original work is properly cited, appropriate credit is given, any changes made indicated, and the use is non-commercial. See: http://creativecommons.org/licenses/by-nc/4.0/. 
ORCID iD

Chia-Hung Kao http://orcid.org/0000-0002-6368-3676

\section{REFERENCES}

1 Gabrielli A, Avvedimento EV, Krieg T. Scleroderma. N Engl J Med 2009;360:1989-2003.

2 Sobanski V, Giovannelli J, Allanore Y, et al. Phenotypes determined by cluster analysis and their survival in the prospective European scleroderma trials and research cohort of patients with systemic sclerosis. Arthritis Rheumatol 2019;71:1553-70.

3 Sobanski V, Launay D, Hachulla E, et al. Current approaches to the treatment of Systemic-Sclerosis-Associated pulmonary arterial hypertension (SSc-PAH). Curr Rheumatol Rep 2016;18:10.

4 Chifflot H, Fautrel B, Sordet C, et al. Incidence and prevalence of systemic sclerosis: a systematic literature review. Semin Arthritis Rheum 2008;37:223-35.

5 Saketkoo LA, Magnus JH, Doyle MK. The primary care physician in the early diagnosis of systemic sclerosis: the cornerstone of recognition and hope. Am J Med Sci 2014;347:54-63.

6 Hirsch AT, Duval S. The global pandemic of peripheral artery disease. Lancet 2013;382:1312-4.

7 Olin JW, Sealove BA. Peripheral artery disease: current insight into the disease and its diagnosis and management. Mayo Clin Proc 2010;85:678-92.

8 Hirsch AT, Haskal ZJ, Hertzer NR, et al. ACC/AHA 2005 practice guidelines for the management of patients with peripheral arterial disease (lower extremity, renal, mesenteric, and abdominal aortic): a collaborative report from the American association for vascular Surgery/Society for vascular surgery, Society for cardiovascular angiography and interventions, Society for vascular medicine and biology, society of interventional radiology, and the ACC/AHA Task force on practice guidelines (writing Committee to develop guidelines for the management of patients with peripheral arterial disease): endorsed by the American association of cardiovascular and pulmonary rehabilitation; National heart, lung, and blood Institute; Society for vascular nursing; transatlantic Inter-Society consensus; and vascular disease Foundation. Circulation 2006;113:e463-654.

9 McDermott MM, Greenland P, Liu K, et al. Leg symptoms in peripheral arterial disease: associated clinical characteristics and functional impairment. JAMA 2001;286:1599-606.

10 Fowkes FGR, Rudan D, Rudan I, et al. Comparison of global estimates of prevalence and risk factors for peripheral artery disease in 2000 and 2010: a systematic review and analysis. Lancet 2013;382:1329-40.

11 Krishna SM, Moxon JV, Golledge J. A review of the pathophysiology and potential biomarkers for peripheral artery disease. Int $J \mathrm{Mol}$ Sci 2015;16:11294-322.

12 Dhamoon MS, Elkind MSV. Inclusion of stroke as an outcome and risk equivalent in risk scores for primary and secondary prevention of vascular disease. Circulation 2010;121:2071-8.

13 Hiatt WR. Medical treatment of peripheral arterial disease and claudication. N Engl J Med 2001;344:1608-21.

14 Hirsch AT, Duval S. The global pandemic of peripheral artery disease. Lancet 2013;382:1312-4.

15 Au K, Singh MK, Bodukam V, et al. Atherosclerosis in systemic sclerosis: a systematic review and meta-analysis. Arthritis Rheum 2011;63:2078-90.

16 Psarras A, Soulaidopoulos S, Garyfallos A, et al. A critical view on cardiovascular risk in systemic sclerosis. Rheumatol Int 2017;37:85-95.

17 Soriano A, Afeltra A, Shoenfeld Y. Is atherosclerosis accelerated in systemic sclerosis? novel insights. Curr Opin Rheumatol 2014;26:653-7.

18 Ngian G-S, Sahhar J, Wicks IP, et al. Cardiovascular disease in systemic sclerosis--an emerging association? Arthritis Res Ther 2011;13:237.

19 Cassius C, Seta V, Monfort J-B, et al. Systemic sclerosis is associated with lower limb vascular stiffness and microvascular impairment: results from a prospective study. Clin Rheumatol 2021;40:3679-86.

20 Elhai M, Meune C, Boubaya M, et al. Mapping and predicting mortality from systemic sclerosis. Ann Rheum Dis 2017;76:1897-905.

21 Database NHIR. Taiwan, 2015. Available: http://nhird.nhri.org.tw/en/ index.html

22 Hsu Y-H, Muo C-H, Liu C-Y, et al. Hepatitis C virus infection increases the risk of developing peripheral arterial disease: a 9-year population-based cohort study. J Hepatol 2015;62:519-25.
23 Lee C-C, Lee M-TG, Chen Y-S, et al. Risk of aortic dissection and aortic aneurysm in patients taking oral fluoroquinolone. JAMA Intern Med 2015;175:1839-47.

24 Chen S-C, Su H-M, Chang J-M, et al. Increasing prevalence of peripheral artery occlusive disease in hemodialysis patients: a 2-year follow-up. Am J Med Sci 2012;343:440-5.

25 Yu K-H, See L-C, Kuo C-F, et al. Prevalence and incidence in patients with autoimmune rheumatic diseases: a nationwide populationbased study in Taiwan. Arthritis Care Res 2013;65:244-50.

26 Chung W-S, Lin C-L, Sung F-C, et al. Systemic sclerosis increases the risks of deep vein thrombosis and pulmonary thromboembolism: a nationwide cohort study. Rheumatology 2014;53:1639-45.

27 Chen Y-J, Lin M-S, Hsu K-Y, et al. Prevalence of asymptomatic peripheral arterial disease and related risk factors in younger and elderly patients in Taiwan. Angiology 2014;65:396-401.

28 Man A, Zhu Y, Zhang Y, et al. The risk of cardiovascular disease in systemic sclerosis: a population-based cohort study. Ann Rheum Dis 2013;72:1188-93.

29 Zeng Y, Li M, Xu D, et al. Macrovascular involvement in systemic sclerosis: evidence of correlation with disease activity. Clin Exp Rheumatol 2012;30:S76-80.

30 Nordin A, Jensen-Urstad K, Björnådal L, et al. Ischemic arterial events and atherosclerosis in patients with systemic sclerosis: a population-based case-control study. Arthritis Res Ther 2013;15:R87.

31 Moro L, Pedone C, Scarlata S, et al. Endothelial dysfunction in chronic obstructive pulmonary disease. Angiology 2008;59:357-64.

32 Lin M-S, Hsu K-Y, Chen Y-J, et al. Prevalence and risk factors of asymptomatic peripheral arterial disease in patients with COPD in Taiwan. PLoS One 2013;8:e64714.

33 Lüscher TF. An update on heart failure and peripheral arterial disease. Eur Heart J 2015;36:885-7.

34 Vitiello D, Harel F, Touyz RM, et al. Changes in cardiopulmonary reserve and peripheral arterial function concomitantly with subclinical inflammation and oxidative stress in patients with heart failure with preserved ejection fraction. Int J Vasc Med 2014;2014:1-8.

35 Dutta A, Henley W, Lang IA, et al. The coronary artery diseaseassociated 9p21 variant and later life 20-year survival to cohort extinction. Circ Cardiovasc Genet 2011;4:542-8.

36 Cassar A, Poldermans D, Rihal CS, et al. The management of combined coronary artery disease and peripheral vascular disease. Eur Heart J 2010;31:1565-72.

37 Dimitroulas T, Sandoo A, Kitas GD. Asymmetric dimethylarginine as a surrogate marker of endothelial dysfunction and cardiovascular risk in patients with systemic rheumatic diseases. Int $\mathrm{J} \mathrm{Mol} \mathrm{Sci}$ 2012;13:12315-35.

38 Pagkopoulou E, Arvanitaki A, Daoussis D, et al. Comorbidity burden in systemic sclerosis: beyond disease-specific complications. Rheumatol Int 2019;39:1507-17.

39 Boulanger CM, Scoazec A, Ebrahimian T, et al. Circulating microparticles from patients with myocardial infarction cause endothelial dysfunction. Circulation 2001;104:2649-52.

40 Hettema ME, Bootsma H, Kallenberg CGM. Macrovascular disease and atherosclerosis in SSC. Rheumatology 2008;47:578-83.

41 Baraut J, Michel L, Verrecchia F, et al. Relationship between cytokine profiles and clinical outcomes in patients with systemic sclerosis. Autoimmun Rev 2010;10:65-73.

42 Boin F, Franchini S, Colantuoni E, et al. Independent association of anti-beta(2)-glycoprotein I antibodies with macrovascular disease and mortality in scleroderma patients. Arthritis Rheum 2009;60:2480-9.

43 Meune C, Vignaux O, Kahan A, et al. Heart involvement in systemic sclerosis: evolving concept and diagnostic methodologies. Arch Cardiovasc Dis 2010;103:46-52.

44 Ullah W, Sattar Y, Darmoch F, et al. The impact of peripheral arterial disease on patients with mechanical circulatory support. Int $J$ Cardiol Heart Vasc 2020;28:100509.

45 Dimitroulas T, Giannakoulas G, Karvounis $\mathrm{H}$, et al. Micro- and macrovascular treatment targets in scleroderma heart disease. Curr Pharm Des 2014;20:536-44.

46 Lee KS, Kronbichler A, Eisenhut M, et al. Cardiovascular involvement in systemic rheumatic diseases: an integrated view for the treating physicians. Autoimmun Rev 2018;17:201-14.

47 Zhang L, Wan Y-N, Zhao J-H, et al. The association between systemic sclerosis, arginine and asymmetric dimethylarginine. Inflammation 2015;38:218-23.

48 Butt SA, Jeppesen JL, Torp-Pedersen C, et al. Cardiovascular manifestations of systemic sclerosis: a Danish nationwide cohort study. J Am Heart Assoc 2019;8:e013405.

49 Wang Z, Ni L, Wang J, et al. The protective effect of melatonin on smoke-induced vascular injury in rats and humans: a randomized controlled trial. J Pineal Res 2016;60:217-27. 
50 Rockenschaub P, Nguyen V, Aldridge RW, et al. Data-Driven discovery of changes in clinical code usage over time: a case-study on changes in cardiovascular disease recording in two English electronic health records databases (2001-2015). BMJ Open 2020;10:e034396. 